\title{
Locally Advanced Chordoma
}

National Cancer Institute

\section{Source}

National Cancer Institute. Locally Advanced Chordoma. NCI Thesaurus. Code C153324.

A chordoma that has spread from its original site of growth to nearby tissues. 